\title{
Ether-bond scission in the biodegradation of alcohol ethoxylate nonionic surfactants by Pseudomonas sp. strain SC25A
}

\author{
Edward C. Tidswell, $\uparrow$ Nicholas J. Russell $\ddagger$ and Graham F. White \\ Author for correspondence: Graham F. White. Tel: +44 1222874188 . Fax: +44 1222874116. \\ e-mail: whitegf1@cardiff.ac.uk
}

School of Molecular and Medical Biosciences, University of Wales Cardiff, Museum Avenue, PO Box 911, Cardiff CF1 3US, UK

\begin{abstract}
Pseudomonas sp. strain SC25A, previously isolated for its ability to grow on alcohol ethoxylates (PEG dodecyl ethers) as sole source of carbon and energy, was shown to be capable of growth on the dodecyl ethers of mono-, di, tri- and octaethylene glycols. Comparative growth yields for this series of alcohol ethoxylate nonionic surfactants indicated that, whereas all of the carbon of monoethylene glycol dodecyl ether (MEGDE) was assimilable, only the alkyl chains were assimilated from the higher ethoxamers. These results are interpreted in terms of a primary biodegradation mechanism in which the scission of the dodecyl-ether bond is the first step. In the case of MEGDE this step separates the dodecyl chain from a $C_{2}$ fragment, both of which are readily assimilable; for the higher ethoxamers, the assimilable dodecyl chain is accompanied by an ether-containing PEG derivative which would require further rounds of ether scission before assimilation. Whole cells and cell extracts converted $\left[1-{ }^{14} \mathrm{C}\right] \mathrm{MEGDE}$ initially and very rapidly to radiolabelled dodecanol. Disappearance of $\left[{ }^{14} \mathrm{C}\right]$ dodecanol was accompanied by production of $\left[{ }^{14} \mathrm{C}\right]$ dodecanal. $\left[{ }^{14} \mathrm{C}\right]$ Dodecanoic acid was present at relatively low concentrations throughout the incubation periods. $\left[{ }^{14} \mathrm{C}\right]$ Dodecan-1,12-dioic acid was produced in significant quantities (up to $25 \%$ of radiolabel), and the onset of its production coincided with the peak concentration of dodecanal, the disappearance of which mirrored the appearance of the dioic acid. Under anaerobic conditions in the presence of cell extracts, dodecanol (55\% of radiolabel) and dodecanal ( $22 \%$ ) accumulated rapidly from MEGDE, but there was little subsequent conversion to mono- or dicarboxylic acids. These results are interpreted in terms of a pathway initiated by dodecyl-ether cleavage to produce dodecanol, which is subsequently oxidized to dodecanal and dodecanoic acid. The formation of dodecan-1,12-dioic acid, probably from dodecanal, may represent a means of harbouring carbon under non-growing conditions.
\end{abstract}

Keywords: alcohol ethoxylate, biodegradation, ether scission, nonionic surfactant, ethylene glycol dodecyl ether

\section{INTRODUCTION}

The utility of ethoxylate-based (PEG) nonionic surfactants, such as alkylphenol and linear alcohol ethoxylates

†Present address: William Grant \& Sons Ltd, Girvan Laboratory, Girvan Distillery, Grangestone Industrial Estate, Girvan, Ayrshire KA26 9PT, UK.

$\ddagger$ Present address: Microbiology Laboratories, Department of Biological Sciences, Wye College, University of London, Wye, Ashford, Kent TN25 $5 \mathrm{AH}, \mathrm{UK}$.

Abbreviation: MEGDE, monoethylene glycol dodecyl ether.
(LAE), in detergents and other industrial formulations places them among the most economically important groups of surfactants (Shaw, 1993). As a consequence of their ubiquity, significant quantities of these compounds are either purposefully released into the environment (for example as adjuvants in agrochemicals) or discharged as waste into the environment in domestic and industrial effluents. Assessments of the persistence, environmental impact and acceptability of such compounds require data on several aspects, including their physical translocation within aquatic and terrestrial environments, adsorption to 
solid surfaces, toxicity to aquatic species, biodegradation by micro-organisms, and likely environmental concentrations.

To date, the majority of studies to assess the biodegradability of LAE have used mixed sewage organisms or naturally occurring populations of river-water bacteria (for reviews see Cain, 1977, 1981; Swisher, 1987; White, 1993). The primary biodegradation of LAE is usually accomplished within 1-2 weeks in river-water die-away tests, and in a matter of hours during activated sludge treatment (Swisher, 1987). Using mixed cultures of microorganisms the precise method of LAE primary biodegradation, the identity of the immediate products and the subsequent biochemical routeleading to ultimate biodegradation under aerobic (Steber \& Wierich, 1985) and anaerobic (Steber \& Wierich, 1987) conditions have been identified. Whilst clearly generating an accurate prognosis of the fate of surfactants within natural environments and sewage treatment plants, these studies lend little to the definition of the exact manner and mechanism of microbially mediated primary biodegradation, subsequent routes of metabolism or the direct utilization of these xenobiotic substances as carbon and energy sources by individual species of bacteria.

Three routes have been identified whereby bacteria can initiate biodegradation of LAE (White, 1993), viz. $\omega / \beta$ oxidation of the alkyl chain in the intact surfactant, exocleavage of ethylene glycol $\mathrm{C}_{2}$ units from the PEG moiety, or ether cleavage at the ether bond which joins the PEG chain to the hydrophobic alkyl group (usually referred to as central ether cleavage). For the closely related alcohol ethoxysulfates, all three routes have been identified among four bacterial species tested (Hales et al., 1986; White \& Russell, 1988). In Pseudomonas spp. strains C12B and DES1, ether cleavage occurred at all three ether bonds in dodecyl triethoxysulfate, including the central ether bond, to yield a mixture of metabolites identified as mono-, diand triethyleneglycol sulfates, and the corresponding oxidized products in which the non-sulfated terminus was converted to a carboxylic acid. In the other two isolates, designated strains SC25A and TES5, ether scission of dodecyl triethoxysulfate occurred predominantly at the central (alkyl-) ether bond. Watson \& Jones (1979) also showed that biodegradation of $\left[1-{ }^{14} \mathrm{C}\right]$ dodecyl decaethoxylate by strain SC25A occurred with very rapid evolution of ${ }^{14} \mathrm{CO}_{2}$ concomitant with liberation of decaethoxylate $\left(\mathrm{PEG}_{10}\right)$, again indicative of central ether cleavage. The central alkyl-ether bond is peculiar to nonionic surfactants, as compared to PEGs, and its scission leads at once to total loss of surfactant properties, because it separates the hydrophobic components from the hydrophilic components of the surfactant. Cleavage of this ether bond is thus particularly significant in the context of primary biodegradation of alcohol ethoxylate surfactant.

Several mechanisms have been proposed for bacterial scission of alkyl-O-alkyl and alkyl-O-aryl ether bonds. Monooxygenases have been shown to initiate ether cleavage in dimethyl ether (Stirling \& Dalton, 1980) and methoxy-aromatics (Bernhardt et al., 1975, 1988) by insertion of an oxygen atom at an ether-linked aliphatic carbon to generate a hemiacetal structure, $-\mathrm{CH}_{2}-\mathrm{O}$ $\mathrm{CH}_{2}(\mathrm{OH})$, which spontaneously dissociates to formaldehyde and an alcohol or phenol. Cytochrome P-450 systems also degrade methyl-aryl ethers via a demethylation reaction (Eltis et al., 1993; Karlson et al., 1993), and although direct proof is lacking, this is assumed to proceed via the same pathway. In diaryl ethers, dioxygenation in one of the benzene rings also achieves a hemiacetal intermediate as a precursor of ether cleavage (Schmidt et al., 1992; Wittich et al., 1990).

Where a carbon vicinal to the ether linkage already bears a hydroxyl group (e.g. in a terminal glycol unit $-\mathrm{O}-\mathrm{CH}_{2} \mathrm{CH}_{2} \mathrm{OH}$ ), vitamin- $\mathrm{B}_{12}$-dependent and/or dehydratase-mediated hydroxyl shift mechanisms can operate, especially in anaerobic bacteria, to move the hydroxyl group from terminal to subterminal carbons and thus generate the labile hemiacetal structure (Schink \& Stieb, 1983; Strass \& Schink, 1986; Frings et al., 1992). Pearce \& Heydeman (1980) were first to identify a route involving participation of a vicinal hydroxyl group, although their mechanism involved dehydration to, and subsequent hydrolysis of, a vinyl ether. Thélu et al. (1980) also invoked a mechanism with a vinyl ether intermediate but these authors proposed that the vinyl ether was formed by dehydrogenation to an enol, rather than dehydration. In both cases, however, subsequent rehydration of the $\mathrm{C}=\mathrm{C}$ bond would yield a labile hemiacetal (White et al., 1996).

Pseudomonas sp. strain DES1 metabolized triethylene glycol $\left[1-{ }^{14} \mathrm{C}\right]$ dodecyl ether (dodecyl triethoxylate) by ethoxylate chain-shortening to produce the corresponding diethylene glycol dodecyl ether, monoethylene glycol dodecyl ether (MEGDE) and dodecanol, together with the corresponding products in which each terminal $\mathrm{CH}_{2} \mathrm{OH}$ group was oxidized to $\mathrm{COOH}$ (Griffiths et al., 1987). In addition, a group of metabolites was detected which contained alkyl-ether bonds and carbonyl groups but neither hydroxyl nor acid groups. These were tentatively identified as the aldehydes intermediate between the alcohols and acids just described. However no precursor-product relationships were apparent and the immediate product of ether scission (alcoholic, aldehydic or carboxylic functional group) is unknown.

The present study was undertaken with the bacterium Pseudomonas SC25A, which, in contrast with Pseudomonas DES1, is highly regioselective for the central ether bond. The organism was originally isolated by enrichment from activated sludge for its capacity to use dodecyl decaethoxylate as sole source of carbon and energy (Watson \& Jones, 1979). The objectives were: (a) to determine the ability of this organism to biodegrade and grow at the expense of dodecyl ethers with different ethoxylate chain lengths; (b) to identify the immediate biodegradation products of MEGDE to facilitate subsequent enzymic analysis; and (c) to determine the metabolic fate of the products of primary biodegradation in Pseudomonas SC25A. 


\section{METHODS}

Chemicals. The commercial alcohol ethoxysulfate surfactant Empicol ESB70, containing approximately $70 \%(\mathrm{w} / \mathrm{w})$ alkyl ethoxy sulfates (with alkyl chain lengths from $\mathrm{C}_{10}$ to $\mathrm{C}_{14}$ and mainly two ethoxy units), $3.5 \%$ unsulfated alcohol ethoxylate, $1.5 \%$ sodium sulfate, $0.3 \%$ sodium chloride and the balance as water, was kindly donated by Albright and Wilson. Unlabelled dodecyl ethoxylates (mono-, di-, tri- and octaethylene glycol dodecyl ethers) were obtained from Nikko Chemical. 1Bromo[ $\left[1{ }^{14} \mathrm{C}\right]$ dodecane (specific activity $92 \cdot 2 \mathrm{MBq} \mathrm{mmol}^{-1}$ ) was obtained from Amersham International. All other reagents and chemicals were the purest available from Merck or Sigma. Optifluor liquid scintillation cocktail was obtained from Canberra Packard.

Chemical synthesis of $\left[1-{ }^{14} \mathrm{C}\right] \mathrm{MEGDE}$. Dispersed sodium metal (10 $\mathrm{ml}$ of a $40 \%, \mathrm{w} / \mathrm{v}$, suspension in toluene) was added slowly to $47 \mathrm{mg}$ ethylene glycol and heated to $55^{\circ} \mathrm{C}$ with occasional vortex mixing. After the reaction had stopped (indicated by the cessation of $\mathrm{H}_{2}$ evolution) the reaction mixture was heated to $140^{\circ} \mathrm{C}$ and $1.85 \mathrm{MBq}(5 \mathrm{mg}) 1$-bromo $\left[1{ }^{14} \mathrm{C}\right]$ dodecane was added. Following incubation for a further $5 \mathrm{~h}$ at $140^{\circ} \mathrm{C}$ with occasional vortexing, the reaction mixture was cooled, transferred to a glass sinter and washed with diethyl ether until negligible radioactivity remained on the sinter. The pooled diethyl ether extract was evaporated to dryness, resuspended in a small volume of diethyl ether and applied as a band to a $20 \times 20 \mathrm{~cm}$ preparative silica gel $60 \mathrm{~A}$ TLC plate (Whatman). The chromatogram was developed with toluene/acetone $(4: 1$, $\mathrm{v} / \mathrm{v}$ ) and dried prior to exposure to Kodak X-omat XAR-2 Xray film for periods of $1-10 \mathrm{~d}$ depending upon the amount of radiolabel present. Films were developed in Kodak universal developer (diluted 1:4 with water), then fixed (Kodafix, diluted $1: 3$ with water) and washed with running tap-water for $30 \mathrm{~min}$ prior to drying. The area of silica gel containing the radioactive MEGDE was scraped from the plate and extracted sequentially with diethyl ether and methanol. The extract was evaporated to dryness under $\mathrm{N}_{2}$ and redissolved in $1.5 \mathrm{ml}$ methanol. The radiolabelled MEGDE was authenticated by cochromatography with unlabelled MEGDE using radio-GLC analysis.

Media and growth conditions. Bacteria were grown in a minimal medium (MM) containing $\left(\mathrm{g} \mathrm{l}^{-1}\right): \mathrm{K}_{2} \mathrm{HPO}_{4}, 3.5$; $\mathrm{KH}_{2} \mathrm{PO}_{4}, 1.5 ; \mathrm{NH}_{4} \mathrm{Cl}, 0.5 ; \mathrm{MgCl}_{2} .6 \mathrm{H}_{2} \mathrm{O}, 0.15 ; \mathrm{NaCl}, 0.5$; $\mathrm{Na}_{2} \mathrm{SO}_{4}, 0 \cdot 14$. Batch cultures were grown in $\mathrm{MM}$ supplemented with $0.03 \%(\mathrm{w} / \mathrm{v})$ yeast extract plus $0.05 \%(\mathrm{w} / \mathrm{v})$ alcohol ethoxylate at $30^{\circ} \mathrm{C}$ and shaking at 120 r.p.m. Culture growth was followed spectrophotometrically (Pharmacia LKB Novaspek II spectrophotometer) at $680 \mathrm{~nm}$ after dilution with methanol, which solubilized residual water-insoluble droplets of nonionic surfactant.

Pseudomonas SC25A was maintained at room temperature on MM solidified with $1 \%(\mathrm{w} / \mathrm{v})$ agarose and supplemented with $0.03 \%(\mathrm{w} / \mathrm{v})$ yeast extract plus $0.05 \%(\mathrm{w} / \mathrm{v})$ Empicol ESB70.

Preparation of cell extracts. Bacteria were harvested by centrifugation $\left(8300 \boldsymbol{g}_{\text {av. }}\right.$ for $10 \mathrm{~min}$ ) from the stationary phase of batch culture, washed and resuspended (to approximately $20 \mathrm{mg}$ dry weight cells $\mathrm{ml}^{-1}$ ) in MM. The bacteria were disrupted by passage at $0^{\circ} \mathrm{C}$ through a chilled French pressure cell (Aminco) operated at $120 \mathrm{MPa}$. Light-microscopic examination showed that bacterial disruption was $>95 \%$.

Radiorespirometry. Aliquots $(0.5 \mathrm{ml})$ of either a bacterial cell suspension (containing 2-4 mg dry weight cells $\mathrm{ml}^{-1}$ ) or cell extracts (containing approximately $4 \mathrm{mg}$ protein $\mathrm{ml}^{-1}$ ) were incubated with $\left[1-{ }^{14} \mathrm{C}\right] \mathrm{MEGDE}$ (final concentration $17 \mu \mathrm{M}$ ) in a series of two-compartment sealed reaction vials similar to the radiorespirometer described by Griffiths et al. (1987). The use of a Suba-seal stopper in place of the normal cap permitted the exchange of the reaction vial atmosphere with $\mathrm{N}_{2}$ via hypodermic needles to generate anaerobic conditions when required. Biodegradation was initiated by addition of the bacterial cell suspension or cell extract to $0.8 \mathrm{kBq}$ [1${ }^{14} \mathrm{C}$ MEGDE in the outer compartment. Liberated ${ }^{14} \mathrm{CO}_{2}$ was trapped on filter paper containing $60 \mu \mathrm{l} 5 \mathrm{M} \mathrm{NaOH}$ placed in the inner compartment. Addition of $0.5 \mathrm{ml} 20 \%$ (w/v) trichloroacetic acid at timed intervals to the incubation medium served to stop the biodegradation and promote transfer of ${ }^{14} \mathrm{CO}_{2}$ to the filter paper. After equilibration for $3 \mathrm{~h}$ at $37^{\circ} \mathrm{C}$ the filter paper was removed and placed in a Wheaton vial containing $15 \mathrm{ml}$ Optifluor liquid scintillation cocktail. After a further $6 \mathrm{~h}$ incubation in the dark, the radioactivity was measured using a LKB-Wallac 1217 Rackbeta liquid scintillation counter (Pharmacia-LKB). Counting efficiency was established by the external-standard channels-ratio method using [1${ }^{14} \mathrm{C}$ ]hexadecane as standard and diethyl ether or filter paper containing $\mathrm{NaOH}$ as the quenching agent. Control experiments in which incubation medium was replaced with standard solutions of sodium $\left[{ }^{14} \mathrm{C}\right]$ bicarbonate showed that recovery of ${ }^{14} \mathrm{CO}_{2}$ was $>92 \%$ of the theoretical amount. Each acidified biodegradation mixture was removed and extracted with diethyl ether $(3 \times 5 \mathrm{ml})$. The pooled diethyl ether extract $(15 \mathrm{ml})$ was back-washed separately with $3 \mathrm{ml}$ distilled water, then dried over anhydrous sodium sulfate and evaporated to dryness under $\mathrm{N}_{2}$. Radioactivity of the residual aqueous phase of the reaction mixture was determined by addition of a small measured volume to $5 \mathrm{ml}$ Optifluor in a Wheaton vial for scintillation counting. The diethyl-ether-extractable residues were redissolved in a small volume of diethyl ether, a portion of which was used to determine the radioactivity, and the remainder was analysed by two-dimensional TLC.

Two-dimensional TLC and quantification of ${ }^{14} \mathrm{C}$-labelled metabolites. Extracts from biodegradation reactions were applied to Baker-flex IB2 silica gel plates (J. T. Baker), cut to $10 \times 10 \mathrm{~cm}$ size, and developed in the first dimension with toluene/acetone $(4: 1, \mathrm{v} / \mathrm{v})$ and in the second dimension with toluene/acetone/acetic acid ( $8: 2: 1$, by vol.). Radioactive areas on the TLC plates were identified by autoradiography, and the silica gel from these areas was removed and placed in a Wheaton vial containing $5 \mathrm{ml}$ Optifluor for quantification of radioactivity. Metabolites were identified by comparison of mobilities with those of $\left[1-{ }^{14} \mathrm{C}\right]$ dodecanoic acid, unlabelled dodecanoic acid, dodecanol, dodecanal, 1,12-dodecandioic acid and 12hydroxydodecanoic acid. Unlabelled standards were detected on developed TLC plates by spraying with $50 \%$ (v/v) sulfuric acid, heating at $105^{\circ} \mathrm{C}$ for $2 \mathrm{~h}$, and incubating briefly in $\mathrm{I}_{2}$ vapour.

\section{Chemical modification of ${ }^{14} \mathrm{C}$-labelled metabolites}

Hydrobromic acid cleavage of ether bonds. Diethyl-ether-extracted residues $(0.1 \mathrm{ml})$ were treated with $0.2 \mathrm{ml} 48 \%(\mathrm{w} / \mathrm{v})$ hydrobromic acid, and incubated for $24 \mathrm{~h}$ at $100{ }^{\circ} \mathrm{C}$. A fter cooling, the mixture was extracted six times with diethyl ether $(0.2 \mathrm{ml}$ aliquots); the pooled ether extract $(1.2 \mathrm{ml})$ was back-washed with distilled water, dried over anhydrous sodium sulfate and evaporated to dryness under $\mathrm{N}_{2}$. The residue was resuspended in a minimum volume of diethyl ether and analysed by TLC.

Conversion of carbonyl groups to 2,4-dinitrophenylhydrazones. Diethyl-ether-extracted residues $(0.1 \mathrm{ml})$ were mixed with $0.2 \mathrm{ml}$ $20 \mathrm{mM}$ 2,4-dinitrophenylhydrazine in $95 \%(\mathrm{v} / \mathrm{v})$ ethanol. After addition of $0.2 \mathrm{ml} 1 \mathrm{M} \mathrm{H}_{2} \mathrm{SO}_{4}$ the mixture was incubated at $70{ }^{\circ} \mathrm{C}$ for $20 \mathrm{~min}$. After cooling, the modified metabolites were extracted six times with hexane $(0.2 \mathrm{ml}$ aliquots $)$; the pooled extract $(1.2 \mathrm{ml})$ was back-washed with water, dried over 
anhydrous sodium sulfate and evaporated to dryness under $\mathrm{N}_{2}$. The residue was resuspended in a minimum volume of diethyl ether and analysed by TLC.

GLC analysis of surfactants. (Poly)ethylene glycol dodecyl ethers were quantified by GLC on $5 \%$ (w/v) SP2100 supported on 80-100 mesh Supelcoport (Supelco) packed in a glass column ( $3 \mathrm{~m} \times 3 \mathrm{~mm}$ internal diameter) operated isothermally at 220 , 250,280 or $320^{\circ} \mathrm{C}$ for mono-, di-, tri- or octaethylene glycol dodecyl ethers, respectively. The injector and detector temperatures were $350{ }^{\circ} \mathrm{C}$, and the carrier gas was $\mathrm{N}_{2}$ at a flow rate of approximately $60 \mathrm{ml} \mathrm{min}^{-1}$.

\section{RESULTS}

\section{Utilization of dodecyl ethers as growth substrates}

Aerobic growth of Pseudomonas SC25A on $0.03 \%$ yeast extract was exponential (Fig. 1) and reached stationary phase $(0 \cdot 1$ OD units) in about $7 \mathrm{~h}$ with a generation time of $2.3 \mathrm{~h}$. Supplementing the yeast extract medium with

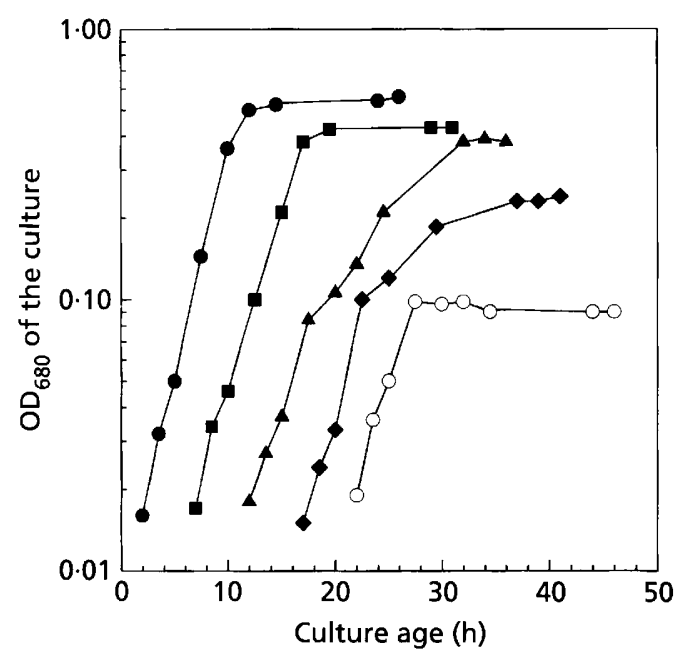

Fig. 1. Growth of Pseudomonas SC25A in batch culture on minimal medium containing $0.03 \%(\mathrm{w} / \mathrm{v})$ yeast extract alone (O) and supplemented with $0.05 \%$ (w/v) MEGDE (O), diethylene glycol dodecyl ether ( $\square$ ), triethylene glycol dodecyl ether $(\boldsymbol{\Delta})$ and octaethylene glycol dodecyl ether $(\boldsymbol{\Delta})$. An $\mathrm{OD}_{680}$ of 1.0 was equivalent to $0.9 \mathrm{mg}$ cell dry weight (ml medium) ${ }^{-1}$. All culture flasks were inoculated simultaneously, but for clarity of presentation the growth curves for yeast extract supplemented with mono-, di-, tri- and octaethylene glycol dodecyl ethers and for yeast extract alone are shown displaced to the right by $0,5,10,15$ and $20 \mathrm{~h}$, respectively. mono-, di-, tri- or octaethylene glycol dodecyl ethers produced little change in growth kinetics up to $0 \cdot 1 \mathrm{OD}$ units (generation times $1.70,2.02,2.14$ and $1.96 \mathrm{~h}$, respectively). Above this level of growth, the growth rate became dependent on the surfactant present. Supplements of mono- or diethylene glycol dodecyl ethers prolonged growth at the initial rate, whereas tri- and octaethylene glycol dodecyl ethers produced distinctly biphasic growth curves, with significantly longer generation times in the second phase ( $6 \mathrm{~h}$ and $9.5 \mathrm{~h}$, respectively). In addition, the growth yields decreased as the number of ethylene glycol units in the surfactant molecule increased. The specific growth yields are shown in Table 1, expressed as either cell dry weight per mol total (alkyl plus ethoxylate) carbon, or cell dry weight per mol alkyl chain carbon only.

\section{Biodegradation of $\left[1-{ }^{14} \mathrm{C}\right] \mathrm{MEGDE}$ by whole cells and cell extracts of Pseudomonas SC25A}

Incubation of intact cells of Pseudomonas SC25A with [1${ }^{14}$ C]MEGDE produced an initial rapid decrease in the diethyl-ether-extractable ${ }^{14} \mathrm{C}$-labelled material, declining from $100 \%$ (reflecting the lipophilic nature of the parent surfactant) to $65 \%$ of the total recovered radiolabel after 20 min (Fig. 2). Concurrently, radiolabel appeared in liberated ${ }^{14} \mathrm{CO}_{2}$ and in the aqueous residue. Subsequent changes in the amount of liberated ${ }^{14} \mathrm{CO}_{2}$ and diethylether-extractable ${ }^{14} \mathrm{C}$-labelled components were slower. Throughout this and all subsequent experiments the amount of radioactivity retained in the aqueous residue following diethyl ether extraction remained almost constant after the initial few minutes of incubation.

When cell extracts of Pseudomonas SC25A were employed to biodegrade $\left[1-{ }^{14} \mathrm{C}\right] \mathrm{MEGDE}$, a similar but considerably slower release of ${ }^{14} \mathrm{CO}_{2}$ was detected; generation of an amount of ${ }^{14} \mathrm{CO}_{2}$ comparable to that released during the initial $4 \mathrm{~min}$ of whole-cell biodegradations required $>200$ min incubation with cell-free extracts (data not shown). In all samples removed during the time-course of whole-cell and cell-extract-mediated biodegradation of $\left[1-{ }^{14} \mathrm{C}\right] \mathrm{MEGDE}$, the total recovered radiolabel was $>94 \%$ of the initial total radiolabel supplied. Incubation of $\left[1-{ }^{14} \mathrm{C}\right] \mathrm{MEGDE}$ with cell-free spent culture medium produced no detectable changes in the distribution of radiolabel between aqueous, diethyl ether or gaseous fractions.

Table 1. Comparative yields of Pseudomonas SC25A grown on alcohol ethoxylates

\begin{tabular}{|lcc|}
\hline Surfactant & $\begin{array}{c}\text { Cell yield [g cell dry weight (mol carbon) }{ }^{-1} \text { ] } \\
\text { based on the utilization of: }\end{array}$ \\
\cline { 2 - 3 } & All carbon & Alkyl carbon only \\
\hline Monoethylene glycol dodecyl ether & $\mathbf{1 3 \cdot 7}$ & 16.0 \\
Diethylene glycol dodecyl ether & $10 \cdot 3$ & $\mathbf{1 3 \cdot 7}$ \\
Triethylene glycol dodecyl ether & $9 \cdot 0$ & $\mathbf{1 3 . 6}$ \\
Octaethylene glycol dodecyl ether & $4 \cdot 9$ & 11.6 \\
\hline
\end{tabular}




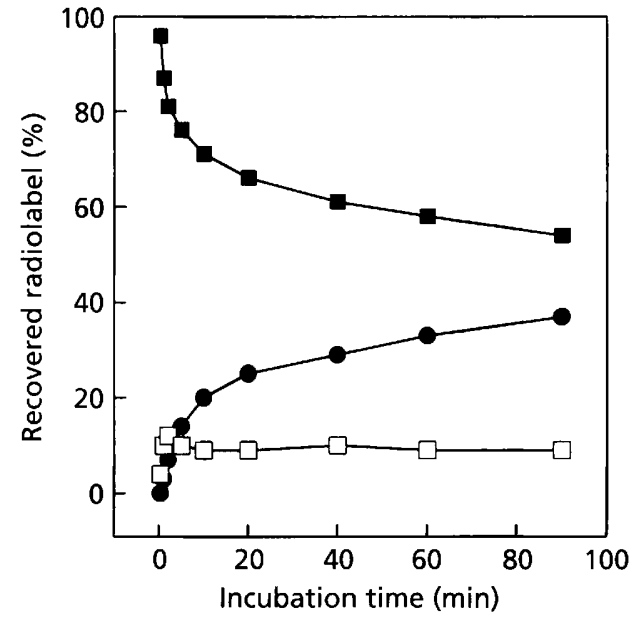

Fig. 2. Distribution of ${ }^{14} \mathrm{C}$ radioactivity during the whole-cell biodegradation of $\left[1-{ }^{14} \mathrm{C}\right] \mathrm{MEGDE}$. See text for radiorespirometry methodology. Radiolabelled substrate $(819 \mathrm{~Bq})$ was added to each vial, and its redistribution among the compartments $\mathrm{CO}_{2}$ $(O)$, diethyl ether extract $(\boldsymbol{\square})$ and aqueous residue $(\square)$ was measured at the indicated times. For this particular experiment mean recovery $( \pm S D)$ of the added radiolabel for all vials was $803 \pm 37 \mathrm{~Bq}$, corresponding to $98 \pm 4.5 \%$. The data are presented as the percentage of the total radiolabel recovered from each vial.

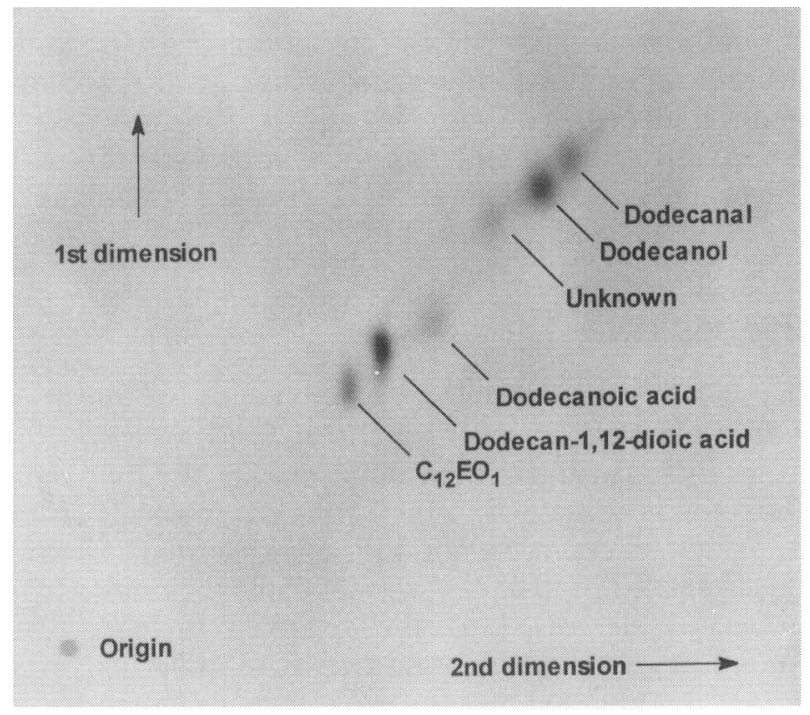

Fig. 3. Two-dimensional TLC autoradiograph illustrating the production of metabolites during the whole-cell biodegradation of $\left[1-{ }^{14} \mathrm{C}\right] \mathrm{MEGDE}$.

\section{Identification of ${ }^{14} \mathrm{C}$-labelled metabolites from $\left[1-{ }^{-14} \mathrm{C}\right] \mathrm{MEGDE}$}

Two-dimensional TLC analysis and autoradiography of diethyl-ether-extracted ${ }^{14} \mathrm{C}$-labelled material from the whole-cell (Fig. 3) and cell-extract (not shown)-mediated biodegradation of $\left[1-{ }^{14} \mathrm{C}\right] \mathrm{MEGDE}$ revealed five major metabolites which were characterized by three methods.

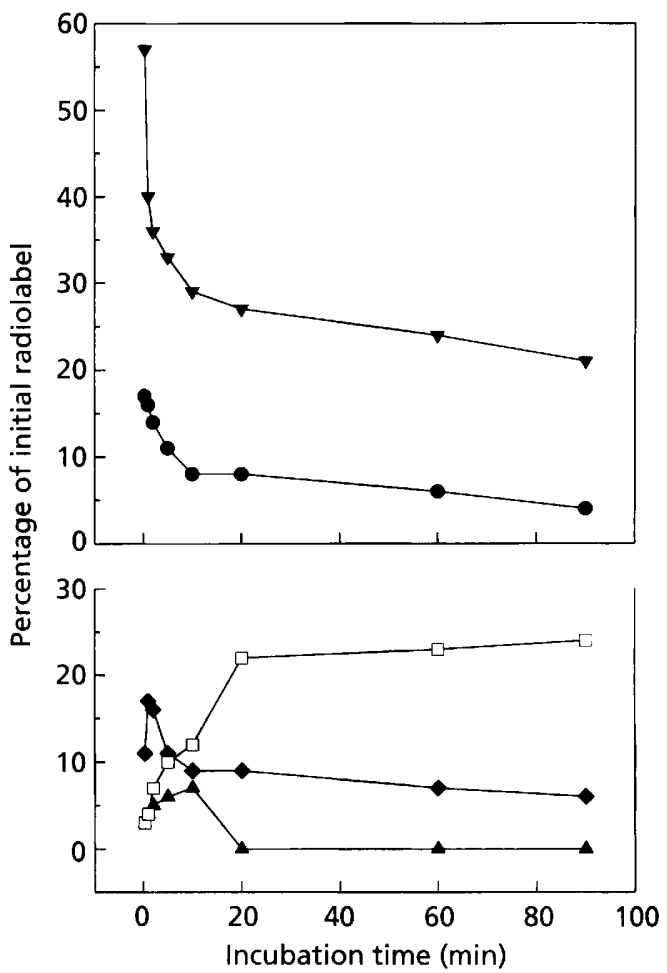

Fig. 4. Production of diethyl-ether-extractable ${ }^{14} \mathrm{C}$-labelled metabolites during the whole-cell biodegradation of [1$\left.{ }^{14} \mathrm{C}\right]$ MEGDE. MEGDE; $\boldsymbol{\nabla}$, dodecanol; $\forall$, dodecanal; dodecanoic acid; $\square \alpha, \omega$-dodecan-1,12-dioic acid. The $100 \%$ value corresponds to the total radiolabel in the substrate initially added to each radiorespirometry vial, which was $819 \mathrm{~Bq}$ (see Fig. 2).

(i) Cleavage of ether bonds by hydrobromic acid treatment prior to two-dimensional TLC analysis indicated that MEGDE was the only material present containing an ether bond. (ii) 2,4-Dinitrophenylhydrazine modification of metabolites and subsequent two-dimensional TLC analysis confirmed that only one alkanal was present and that this co-chromatographed with dodecanal. (iii) Inclusion of $\mathrm{NH}_{3}(1 \%, \mathrm{v} / \mathrm{v}, 0.880$ specific gravity ammonia solution) in the solvent system during development of the chromatogram in the second dimension retarded the mobilities of three metabolites, thereby indicating the presence of acidic functional groups; two of these metabolites co-chromatographed with dodecanoic acid and dodecan-1,12-dioic acid. The third metabolite, although shown to contain an acidic functional group, did not co-chromatograph with any of the available standards and therefore remained unidentified (see Fig. 3).

\section{Quantification of ${ }^{14} \mathrm{C}$-labelled metabolites}

The results of quantification of the ${ }^{14} \mathrm{C}$-labelled metabolites from the whole-cell biodegradation of [1${ }^{14}$ C]MEGDE are illustrated in Fig. 4. Dodecanol was the initial alkyl-based product of MEGDE primary biodegradation, and was the major metabolite throughout almost the entire duration of the experiment. The amount of 


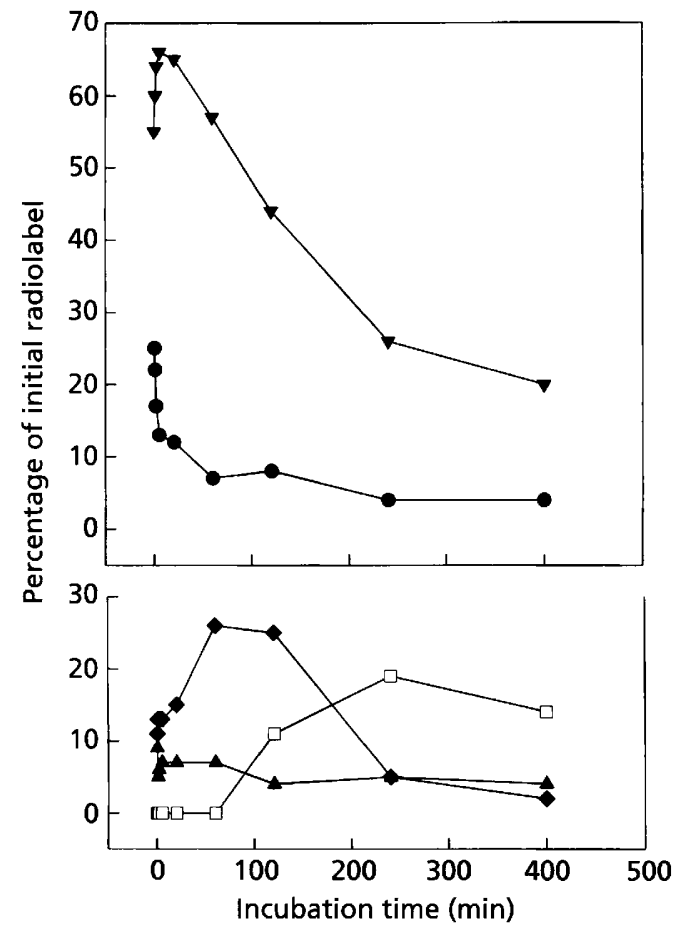

Fig. 5. Production of diethyl-ether-extractable ${ }^{14} \mathrm{C}$-labelled metabolites during the biodegradation of $\left[1-{ }^{14} \mathrm{C}\right] \mathrm{MEGDE}$ by cell extracts. - MEGDE; $\boldsymbol{\nabla}$, dodecanol; $\bullet$, dodecanal; $\boldsymbol{\Delta}$, dodecanoic acid; $\square, \alpha, \omega$-dodecan-1,12-dioic acid. The $100 \%$ value corresponds to the total radiolabel in the substrate initially added to each radiorespirometry vial, which was $819 \mathrm{~Bq}$ (see Fig. 2).

$\left[{ }^{14} \mathrm{C}\right]$ dodecanol diminished rapidly over the first $10 \mathrm{~min}$ of incubation, whilst the quantity of $\left[{ }^{14} \mathrm{C}\right]$ dodecanal increased to $17 \%$ of the initial total radiolabel over the first $2 \mathrm{~min}$ and then subsequently declined to an almost constant level of approximately $9 \%$ within a further $8 \mathrm{~min}$. Amounts of $\left[{ }^{14} \mathrm{C}\right]$ dodecanoic acid declined after an initial increase from $2 \%$ to $6 \%$ over the initial $10 \mathrm{~min}$ of incubation, falling to $0 \%$ within $20 \mathrm{~min}$. In parallel with the pattern of ${ }^{14} \mathrm{CO}_{2}$ release (Fig. 2), the levels of $\left[{ }^{14} \mathrm{C}\right]$ dodecan-1,12-dioic acid increased from $2 \%$ to $21 \%$ of the initial radiolabel during the first $20 \mathrm{~min}$.

Similar analyses of ${ }^{14} \mathrm{C}$-labelled metabolites from the cellfree-mediated biodegradation of $\left[1-{ }^{14} \mathrm{C}\right] \mathrm{MEGDE}$ demonstrated that there was a product-precursor relationship between dodecanol and dodecanal, since the decrease in the amount of $\left[{ }^{14} \mathrm{C}\right]$ dodecanol was coincident with an increase in the amount of $\left[{ }^{14} \mathrm{C}\right]$ dodecanal during the early stages of incubation (Fig. 5). Almost constant amounts of $\left[{ }^{14} \mathrm{C}\right]$ dodecanoic acid ( $\sim 3 \%$ of the total radioactivity) and of the unknown metabolite (data not shown) were observed. Dodecan-1,12-dioic acid accumulated as the final product, but significant amounts of this dicarboxylic acid were present only after the dodecanal concentration had risen to $>25 \%$ of the initial total radioactivity. When the cell-free biodegradation of $\left[1-{ }^{14} \mathrm{C}\right] \mathrm{MEGDE}$ was performed under anaerobic conditions, there was no

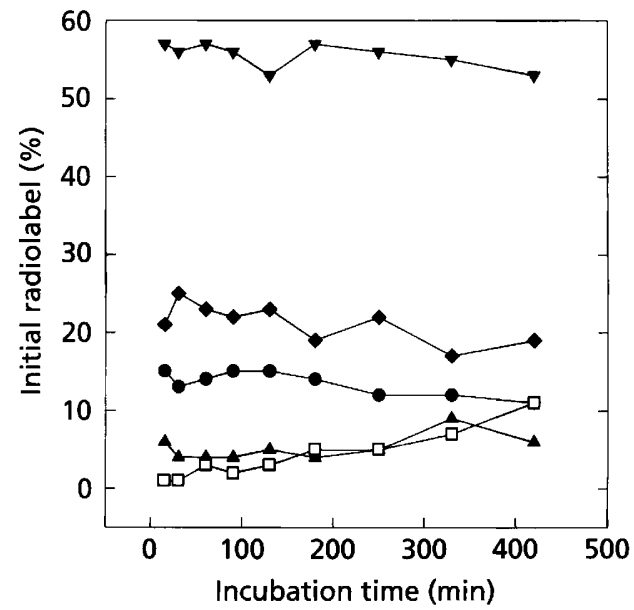

Fig. 6. Production of diethyl-ether-extractable ${ }^{14} \mathrm{C}$-labelled metabolites during the anaerobic biodegradation of [1${ }^{14}$ C]MEGDE by cell extracts. - , MEGDE; $\boldsymbol{\nabla}$, dodecanol; $\bullet$, dodecanal; $\boldsymbol{\Lambda}$, dodecanoic acid; $\square, \alpha, \omega$-dodecan-1,12-dioic acid. The $100 \%$ value corresponds to the total radiolabel in the substrate initially added to each radiorespirometry vial, which was $819 \mathrm{~Bq}$ (see Fig. 2).

effect on the very rapid initial disappearance of the surfactant; however, the subsequent metabolic profile generated under these conditions was quite distinct from those observed under aerobic conditions (Fig. 6). Under anaerobic conditions, dodecanol and dodecanal accumulated rapidly to constant values of $55 \%$ and $20 \%$, respectively, and there was very little generation of dodecanoic acid and dodecan-1,12-dioic acid (neither ever exceeding $10 \%$ of the initial radiolabel).

\section{DISCUSSION}

The data in Fig. 1 showed that the yield of Psendomonas SC25A biomass during growth on PEG dodecyl ether surfactants was apparently influenced by the number of ethoxy units contained in the surfactant molecule. All of the growth curves were conducted with a total surfactant concentration of $0.05 \%(\mathrm{w} / \mathrm{v})$. Thus the molarity of surfactants decreased as the relative ethylene glycol content of the molecule (and therefore molecular mass) increased. Table 1 shows the growth yields (corrected for the initial phase of growth on yeast extract) calculated as cell dry weight (mol carbon $)^{-1}$, assuming either that all the carbon (alkyl chain and ethoxylate, second column) was used for growth or that only the alkyl chain was used (third column). The values based on the assumption of allcarbon utilization decreased markedly as surfactant molecular mass increased, thus invalidating the all-carbon assumption. When only alkyl carbon was assumed to support growth, the values were much closer, showing that the alkyl chain was the dominant carbon source. The values for alkyl-carbon utilization for di- and triethylene glycol dodecyl ethers were very similar to each other and to the all-carbon value for the MEGDE, implying that only the alkyl-carbon was used in the di- and tri- 
homologues but that all of the carbons (i.e. both alkyl chain and ethoxylate moieties) were used in the monohomologue. This is a reasonable conclusion, because ether cleavage of the latter compound yields dodecanol (see below) plus a $\mathrm{C}_{2}$ fragment, both of which are readily assimilable, whereas the di- and triethoxylates probably yield diethylene glycol and triethylene glycol fragments, respectively, neither of which is rapidly assimilated in this organism. The slightly lower growth yield for octaethylene glycol dodecyl ether suggested that there was less efficient use of the dodecyl chain by the bacterium, the reasons for which are unknown.

Kinetics of growth $\left(\mathrm{OD}_{680}>0 \cdot 1\right.$, see Fig. 1) were also affected by the surfactant used. Growth rates of Pseudomonas SC25A in batch cultures using MEGDE or diethylene glycol dodecyl ether as substrate were as high throughout the growth period as that observed for growth on yeast extract alone. However growth on yeast extract supplemented with tri- or octaethylene glycol dodecyl ethers was biphasic and the rates of growth in the second phase, presumably supported by the surfactant supplements, were substantially diminished compared with that achieved by yeast extract alone. Similar biphasic growth at the expense of yeast extract and triethoxylated anionic surfactants has previously been reported for Pseudomonas DES1 (Hales et al., 1982). Slower growth on the higher ethoxylates may arise from the lower molarity of these compounds in the growth medium and therefore of the growth-supporting dodecanol to which they are converted. Alternatively, the rate of enzymic ether cleavage to liberate the growth-supporting dodecanol may be slower for higher ethoxylates.

Identification of dodecanol as the immediate hydrophobic product of MEGDE metabolism showed that ether cleavage of MEGDE was the primary biodegradation step. Other authors also have produced evidence that Pseudomonas SC25A biodegrades both dodecyl triethoxysulfate (Hales et al., 1986) and the nonionic decaethylene glycol dodecyl ether (Watson \& Jones, 1979) via an initial ether cleavage predominantly at the dodecyl-ether bond. The failure of cell-free spent culture medium to accomplish biodegradation of MEGDE showed that the process was not mediated by extracellular enzyme(s), as had previously been implicated for ether scission by other organisms (Haines \& Alexander, 1975; Dwyer \& Tiedje, 1986). The ability of cell-free extracts of Pseudomonas SC25A to mediate ether cleavage in MEGDE under anaerobic conditions indicated that molecular oxygen was not required, which is in contrast with ether scission effected by some other micro-organisms (Crawford $e t$ al., 1973; Bernhardt et al., 1975; Stirling \& Dalton, 1980; Sariaslani, 1991; White et al., 1996). It seems more likely that the ether scission in MEGDE involves participation of the vicinal hydroxyl group. Three mechanisms have previously been proposed for ether cleavage in similar structures. First Pearce \& Heydeman (1980) proposed that Acinetobacter achieved cleavage in PEGs by an initial dehydration of $-\mathrm{O}-\mathrm{CH}_{2} \mathrm{CH}_{2}-\mathrm{OH}$ to $-\mathrm{O}-\mathrm{CH}=\mathrm{CH}_{2}$, followed by hydrolysis of the vinyl ether. White et al. (1996) recently suggested that the apparent hydrolysis step is more likely to occur via hydration of the vinyl ether to the hemiacetal $-\mathrm{O}-\mathrm{CH}(\mathrm{OH}) \mathrm{CH}_{3}$, which is unstable and decomposes spontaneously. Thélu et al. (1980) also proposed a vinyl ether formation but in this case by dehydrogenation of $-\mathrm{O}-\mathrm{CH}_{2} \mathrm{CH}_{2}-\mathrm{OH}$ to $-\mathrm{O}-\mathrm{CH}=\mathrm{CH}-\mathrm{OH}$, followed by hydration to a hemiacetal. In this case, White et al. (1996) suggested that the enol intermediate would be much more likely to arise via oxidation of the hydroxyl to an aldehyde, followed by keto-enol tautomerization. Finally Frings $e t$ al. (1992) and Schramm \& Schink (1991) showed that anaerobic degradation of PEG occurs via a vitamin- $B_{12^{-}}$ dependent hydroxyl shift from the terminal carbon to the ether-linked carbon, again to form the hemiacetal. In all these cases the resulting hemiacetal dissociates to an aldehyde and alcohol, thereby breaking the original ether bond. Operation of such a mechanism in the biodegradation of MEGDE in Pseudomonas SC25A would lead to the observed dodecanol, but it would not be applicable to the higher ethoxylates which lack an hydroxyl group vicinal to the central ether bond. The mechanism implies that the glycol unit in MEGDE should be liberated as acetaldehyde, and experiments are currently in progress to establish this.

Subsequent metabolism of dodecanol generated from MEGDE by cell-free extracts and whole cells of Pseudomonas SC25A appeared to involve oxidation, first to dodecanal and thence to dodecanoic acid, probably by means of NAD-linked dehydrogenases. The dodecanoic acid was further metabolized under aerobic conditions by two routes: (i) during the initial phase of MEGDE biodegradation dodecanoic acid was assimilated via $\beta$ oxidation to liberate $\mathrm{CO}_{2}$, a reaction sequence common to anionic-surfactant-degrading and alkane-utilizing microorganisms (White \& Russell, 1988; Watkinson \& Morgan, 1990); (ii) at later stages of the biodegradation, substantial amounts of dodecyl chains were $\omega$-oxidized, which resulted in the gradual accumulation of dodecan1,12-dioic acid concurrently with a decline in the rate of liberation of $\mathrm{CO}_{2}$. Although dodecan-1,12-dioic acid was firmly identified in the present study, the alcoholic and aldehydic precursors were neither unambiguously identified nor resolved by two-dimensional TLC; the unidentified acidic metabolite may represent the transient accumulation of one or more intermediates in the pathway to dodecan-1,12-dioic acid. The generation of $\alpha, \omega$-dioic acids via di-terminal oxidation of alkanes by microorganisms occurs only rarely (Rehm \& Reiff, 1981). By analogy with the explanation proposed by Broadway $e t a l$. (1993) in accounting for dicarboxylic acid formation with a Corynebacterium strain, the decreased demand for energy by Pseudomonas SC25A under the 'resting cell' conditions imposed in these experiments might lead to lower rates of $\beta$-oxidation, and thus elevated levels of dodecanoic acid might occur which may be more amenable to di-terminal oxidation. Alternatively, the diversion of dodecanoic acid towards the more slowly $\beta$-oxidizable $\alpha$, $\omega$-dioic acids might represent a purposeful strategy adopted by the bacterium as a means of harbouring fuel reserves when encountering nongrowing conditions.

The putative biodegradation pathway shown in Fig. 7 is 


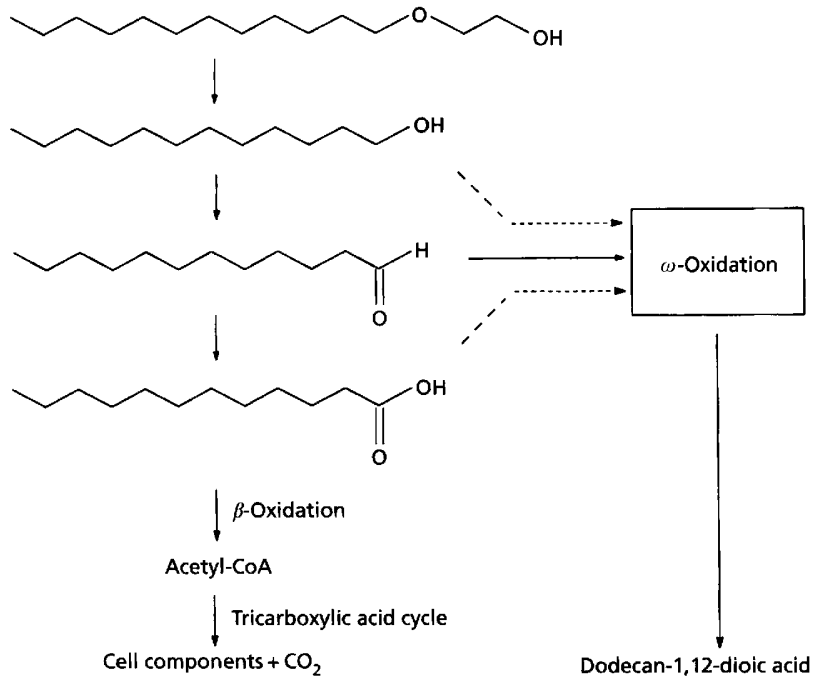

Fig. 7. Putative pathway for the biodegradation of MEGDE by Pseudomonas SC25A.

proposed to account for the data presented. We suggest that Pseudomonas SC25A achieves primary biodegradation of the nonionic surfactant MEGDE by means of an oxygen-independent intracellular ether-scission process, generating dodecanol as the alkyl fission product. The identity of the ethoxy product is unknown. Dodecanol is further metabolized to dodecanal (probably via the agency of NAD-linked alcohol dehydrogenase) and then dodecanoic acid (via aldehyde dehydrogenase), which in turn serves as a substrate for central metabolic pathways leading to the production of $\mathrm{CO}_{2}$. When the primary biodegradation of MEGDE was almost complete ( $>90 \%$, see Fig. 4) and the intermediates dodecanol, dodecanal and dodecanoic acid were no longer increasing in concentration, substantial amounts of the carbon were diverted away from immediate $\beta$-oxidation (yielding $\mathrm{CO}_{2}$ ) towards the formation of dodecan-1,12-dioic acid. The onset of production of dodecan-1,12-dioic acid in cell extracts coincided with the peak concentration of dodecanal, and the appearance of the dioic acid mirrors the disappearance of dodecanal. This suggested that $\omega$ oxidation occurred at one or more stages after the ether scission.

\section{ACKNOWLEDGEMENTS}

This work was supported by the European Union under the PECO programme, contract number ERBCIPACT 923020.

\section{REFERENCES}

Bernhardt, F.-H., Pachowsky, H. \& Staudinger, H. (1975). A 4methoxy O-demethylase from Pseudomonas putida. A new type of monooxygenase system. Eur J Biochem 57, 241-256.

Bernhardt, F.-H., Bill, E., Trautwein, A. X. \& Twilfer, H. (1988). 4Methoxybenzoate monooxygenase from Pseudomonas putida: isolation, biochemical properties, substrate specificity, and reaction mechanism of the enzyme components. Methods Enzymol 161, 281-294.
Broadway, N. M., Dickinson, M. \& Ratledge, C. (1993). The enzymology of dicarboxylic acid formation by Corynebacterium sp. strain 7E1C grown on n-alkanes. J Gen Microbiol 139, 1337-1344.

Cain, R. B. (1977). Surfactant biodegradation in waste waters. In Treatment of Industrial Effuents, pp. 283-327. Edited by A. G. Callely, C. F. Forster \& D. A. Stafford. London: Hodder \& Stoughton.

Cain, R. B. (1981). Microbial degradation of surfactants and 'builder' components. In Microbial Degradation of Xenobiotics and Recalcitrant Compounds, pp. 325-370. Edited by T. Leisinger, R. Hutter, A. M. Cook \& J. Neüsch. London: Academic Press.

Crawford, R. L., McCoy, E., Harkin, J. M., Kirk, T. K. \& Obst, J. R. (1973). Degradation of methoxylated benzoic acids by a Nocardia from a lignin-rich environment: significance to lignin degradation and effect of chloro substituents. Appl Microbiol 26, 176-184.

Dwyer, D. F. \& Tiedje, J. M. (1986). Metabolism of polyethylene glycol by two anaerobic bacteria, Desulfovibrio desulfuricans and a Bacteroides sp. Appl Environ Microbiol 52, 852-856.

Eltis, L. D., Karlson, U. \& Timmis, K. N. (1993). Purification and characterization of cytochrome P-450 from Rhodococcus rhodochrous. Eur J Biochem 213, 211-216.

Frings, J., Schramm, E. \& Schink, B. (1992). Enzymes involved in anaerobic polyethylene glycol degradation by Pelobacter venetianus. Appl Environ Microbiol 58, 2164-2167.

Griffiths, E. T., Hales, S. G., Russell, N. J. \& White, G. F. (1987). Identification of hydrophobic metabolites formed during biodegradation of alkyl ethoxylate and alkyl sulfate surfactants by Pseudomonas sp. DES1. Biotechnol Appl Biochem 9, 217-229.

Haines, J. R. \& Alexander, M. (1975). Microbial degradation of polyethylene glycols. Appl Microbiol 29, 621-625.

Hales, S. G., Dodgson, K. S., White, G. F., Jones, N. \& Watson, G. K. (1982). Initial stages in the biodegradation of the surfactant sodium dodecyltriethoxy sulfate by Pseudomonas sp. strain DES1. Appl Environ Microbiol 44, 790-800.

Hales, S. G., Watson, G. K., Dodgson, K. S. \& White, G. F. (1986). A comparative study of the biodegradation of the surfactant sodium dodecyltriethoxy sulphate by four detergent-degrading bacteria. J Gen Microbiol 132, 953-961.

Karlson, U., Dwyer, D. F., Hooper, S. W., Moore, E. R. B., Timmis, K. N. \& Eltis, L. D. (1993). Two independently regulated cytochromes P-450 in a Rbodococcus rbodocbrous strain that degrades 2ethoxyphenol and 4-methoxybenzoate. J Bacteriol 175, 1467-1474.

Pearce, B. A. \& Heydeman, M. T. (1980). Metabolism of di(ethylene glycol) [2-(2'-hydroxyethoxy)ethanol] and other short poly(ethylene glycol)s by Gram-negative bacteria. J Gen Microbiol 118, 21-27.

Rehm, H. J. \& Reiff, I. (1981). Mechanisms and occurrence of microbial oxidation of long-chain alkanes. Adv Biochem Eng 19, 175-215.

Sariaslani, F. S. (1991). Microbial cytochromes P-450 and xenobiotic metabolism. Adv Appl Microbiol 36, 133-178.

Schink, B. \& Stieb, M. (1983). Fermentative degradation of polyethylene glycol by a strictly anaerobic, Gram-negative, nonsporeforming bacterium, Pelobacter venetianus sp. nov. Appl Environ Microbiol 45, 1905-1913.

Schmidt, S., Wittich, R.-M., Fortnagel, P., Erdmann, D. \& Francke, W. (1992). Metabolism of 3-methyldiphenyl ether by Sphingomonas sp. SS31. FEMS Microbiol Lett 96, 253-258.

Schramm, E. \& Schink, B. (1991). Ether-cleaving enzyme and diol dehydratase involved in anaerobic polyethylene glycol degradation by a new Agrobacterium sp. Biodegradation 2, 71-79. 
Shaw, A. H. (1993). Surfactants update. Soap Cosmet Chem Spec 69, 24-32.

Steber, J. \& Wierich, P. (1985). Metabolites and biodegradation pathways of fatty alcohol ethoxylates in microbial biocenoses of sewage treatment plants. Appl Environ Microbiol 49, 530-537.

Steber, J. \& Wierich, P. (1987). The anaerobic degradation of detergent range fatty alcohol ethoxylates. Studies with ${ }^{14} \mathrm{C}$-labelled model surfactants. Water Res 21, 661-667.

Stirling, D. L. \& Dalton, H. (1980). Oxidation of dimethyl ether, methyl formate and bromomethane by Metbylococcus capsulatus (Bath). J Gen Microbiol 116, 277-283.

Strass, A. \& Schink, B. (1986). Fermentation of polyethylene glycol via acetaldehyde in Pelobacter venetianus. Appl Microbiol Biotechnol 25, $37-42$.

Swisher, R. D. (1987). Surfactant Biodegradation, 2nd edn, vol. 18. Surfactant Science Series. New York: Marcel Dekker.

Thélu, J., Medina, L. \& Pelmont, J. (1980). Oxidation of polyoxyethylene oligomers by an inducible enzyme from Pseudomonas P 400. FEMS Microbiol Lett 8, 187-190.
Watkinson, R. J. \& Morgan, P. (1990). Physiology of aliphatic hydrocarbon-degrading microorganisms. Biodegradation 1, 79-92.

Watson, G. K. \& Jones, N. (1979). The microbial degradation of nonionic surfactants. Soc Gen Microbiol Q 6, 78-79.

White, G. F. (1993). Bacterial biodegradation of ethoxylated surfactants. Pestic Sci 37, 159-166.

White, G. F. \& Russell, N. J. (1988). Mechanisms of bacterial biodegradation of alkyl sulphate and alkylpolyethoxy sulphate surfactants. In Biodeterioration 7, pp. 325-332. Edited by D. R. Houghton, R. N. Smith \& H. O. W. Eggins. London: Elsevier Applied Science.

White, G. F., Russell, N. J. \& Tidswell, E. C. (1996). Bacterial scission of ether bonds. Microbiol Rev 60, 216-232.

Wittich, R.-M., Schmidt, S. \& Fortnagel, P. (1990). Bacterial degradation of 3- and 4-carboxybiphenyl ether by Pseudomonas sp. NSS2. FEMS Microbiol Lett 67, 157-160.

Received 30 August 1995; revised 21 December 1995; accepted 9 January 1996. 